which it is being inserted, which takes up valuable space in the therapeutic agent. And third, the generation of a DSB has an associated risk $^{11}$, albeit a manageable one. Both Peters et al. ${ }^{6}$ and Klompe et al. suggest that the reported transposons provide, in principle, a solution to all those issues: the transposon integration process does not require a DSB at the target (Fig. 1b), or flanking DNA in the therapeutic agent, and should work in nondividing cells. Hence, it could be an attractive approach for human gene editing in the clinic.

However, a long checklist must be completed before clinical applications can be considered seriously. This list includes: showing that the process works efficiently at target genome positions in disease-relevant human cells (rather than in bacteria); demonstrating that it can integrate DNA fragments large enough to be clinically useful; proving its specificity in the human genome, which is about 1,000 times larger than a bacterial one; and developing ways to deliver the full complement of proteins associated with the integration process to cells without triggering the human immune response. This is a formidable workload, but a key lesson of the past 30 years of research into gene therapy is that most challenges of this type are eventually solved ${ }^{7,11,12}$. Therefore, a CRISPR system used by transposons to propagate themselves might well find itself repurposed for genetic medicine.

Fyodor D. Urnov is at the Innovative

Genomics Institute, Berkeley, California

94704, USA.

e-mail:urnov@berkeley.edu

1. Klompe, S. E., Vo, P. L. H., Halpin-Healy, T. S. \& Sternberg, S. H. Nature 571, 219-225 (2019)

2. Peters, J. E., Fricker, A. D., Kapili, B. J.\& Petassi, M. T. Mol. Microbiol. 93, 1084-1092 (2014).

3. Barrangou, R. \& Horvath, P. Nature Microbiol. 2, 17092 (2017).

4. Jinek, M. et al. Science 337, 816-821 (2012).

5. Jiang, F. \& Doudna, J. A. Annu. Rev. Biophys. 46, 505-529 (2017).

6. Peters, J. E., Makarova, K. S., Shmakov, S. \& Koonin, E. V. Proc. Natl Acad. Sci. USA 114, E7358-E7366 (2017).

7. Anguela, X. M. \& High, K. A. Annu. Rev. Med. 70, 273-288 (2019)

8. Carroll, D. Annu. Rev. Biochem. 83, 409-439 (2014).

9. Urnov, F. D. CRISPR J. 1, 34-46 (2018).

10. Moehle, E. A. et al. Proc. Natl Acad. Sci. USA 104, 3055-3060 (2007).

11.Porteus, M. H. N. Engl. J. Med. 380,947-959 (2019).

12.Dunbar, C. E. et al. Science 359, eaan4672 (2018),

This article was published online on 12 June 2019.

\title{
Fishing out a feeding paradox
}

\section{If an animal's body shape is specialized in a way that aids feeding on specific organisms, does this restrict what the animal can prey on? An observation of fishes feeding in the wild might now help to settle this question.}

\section{SEBASTIAN KRUPPERT \& ADAM P. SUMMERS}

A chance observation of fish behaviour, made during an underwater survey along the eastern shore of Lake Tanganyika in Tanzania, has now been reported in American Naturalist by GolcherBenavides and Wagner ${ }^{1}$. Their observation neatly ties together 40 -year-old laboratory data $^{2}$ and a model of evolution based on an idea known as optimal-foraging theory ${ }^{3}$.

The serendipitous event occurred when Golcher-Benavides was on a dive with a Tanzanian colleague, George Kazumbe, studying the species present in a region perpendicular to the lake's shoreline. They saw ahead, sparkling between the lake's surface and its rocky bottom, a massive school of juvenile sardines, estimated to comprise at least 50,000 individuals. Video footage of this event captured what happened when the sardines encountered fishes belonging to a group called the cichlids.
There are about 250 species of cichlid fish in Lake Tanganyika ${ }^{4}$. These species represent fishes that have a wide variety of feeding specializations, including those that have evolved in a way that allows them to target a single type of prey ${ }^{5-7}$, as well as fishes that are capable of eating diverse sources of food. The shapes and features of the heads of some cichlid species bear witness to the adaptation that is suited to their particular food source (Fig. 1).

One example of a cichlid species that has evolved a feeding specialization is Perissodus microlepis. This fish has a curved head, and when it swims alongside a larger fish, it can suddenly attack and snatch a mouthful of scales $^{8}$. The population of this species is split between fish whose head is curved to the left for attacking the right side of its fish prey, and fish whose head is bent rightward to enable an assault on the prey's left side. Other cichlid feeding specializations include those for scraping algae from rocks ${ }^{9}$, biting out the eyes of other fish ${ }^{10}$, and gobbling eggs knocked out

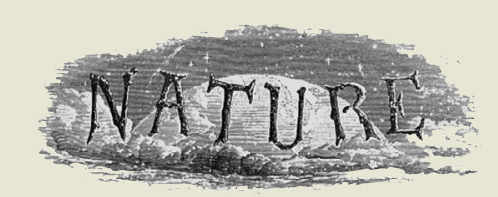

\section{Years Ago}

Assisted by off-stage noises which included a belching elephant seal, a giant toad in mating cry ... and the song of a wren played at slow speed, the British Library of Wildlife Sounds (BLOWS) was opened recently by Mr David Attenborough ... The library ... aims to be the national reference collection of wildlife sounds of all descriptions ... Used in conjunction with other biological reference collections, BLOWS should have an important part to play in research into animal behaviour, taxonomy and evolution ... The library's target is 10,000 recordings (disk or tape) of 2,500 species of animal in five years, and Mr Attenborough appealed for copies of commercial gramophone records ... and for copies of properly documented tape recordings of any animal sound made by either professional or amateur tape recordists.

From Nature 12 July 1969

\section{Years Ago}

In the April issue of the Journal of Mental Science ... Capt. O. P. Napier Pearn describes the differences and similarities in the actual insanities (psychoses) found in military and civil practice... He has collected and tabulated the facts relating to 200 cases which made a sufficiently good recovery to warrant their being returned to duty ... [W] hile at the onset of a mental disorder in civil life the friends and relatives usually co-operate with the sick person in shielding him from medical advice, such a patient in the Army ... is much more likely to receive attention from his medical officer at an early stage. The effect of this early care is that these cases respond to treatment in a very gratifying way ... The article, while laying claim to no new discovery, lays additional emphasis upon the urgency of the early treatment of mental disorders. From Nature 10 July 1919 